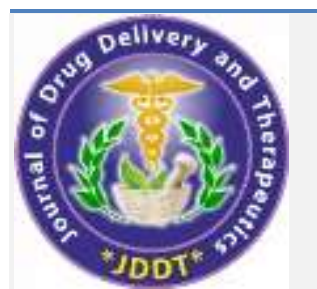

\section{Journal of Drug Delivery and Therapeutics}

Open Access to Pharmaceutical and Medical Research

Copyright (C) 2021 The Author(s): This is an open-access article distributed under the terms of the CC BY-NC 4.0 which permits unrestricted use, distribution, and reproduction in any medium for non-commercial use provided the original author and source are credited

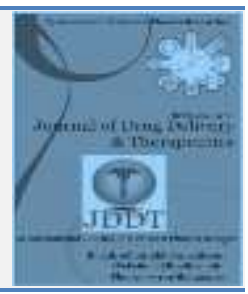

Research Article

\title{
In vitro Comparative Dissolution Studies of Different Propranolol Generic Tablets Available in Bangladesh
}

\author{
Madhabi Lata Shuma ${ }^{1}$, Bishyajit Kumar Biswas², Sheikh Zahir Raihan ${ }^{3}$ and Shimul Halder** \\ ${ }^{1}$ Department of Pharmacy, Stamford University Bangladesh, Siddeswari Dhaka-1217, Bangladesh \\ ${ }^{2}$ Department of Pharmacy, Jagannath University, Dhaka-1100, Bangladesh \\ ${ }^{3}$ Department of Clinical Pharmacy and Pharmacology, Faculty of Pharmacy, University of Dhaka, Dhaka-1000, Bangladesh \\ ${ }^{4}$ Department of Pharmaceutical Technology, Faculty of Pharmacy, University of Dhaka, Dhaka-1000, Bangladesh
}

\section{Article Info:}

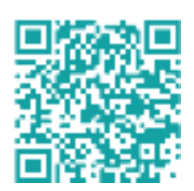

Article History:

Received 11 October 2021

Reviewed 30 November 2021

Accepted 07 December 2021

Published 15 December 2021

\section{Cite this article as:}

Shuma ML, Biswas BK, Raihan SZ, Halder S, In vitro Comparative Dissolution Studies of Different Propranolol Generic Tablets Available in Bangladesh, Journal of Drug Delivery and Therapeutics. 2021 11(6-S):86-91

DOI: http://dx.doi.org/10.22270/jddt.v11i6-S.5225

\section{Abstract}

\begin{abstract}
The present study focused to assess in vitro dissolution profiles of four different products of propranolol $10 \mathrm{mg}$ Tablets (Randomly coded as PRP1-PRP4) available in Bangladesh comparing with the reference brand (coded as REF). Propranolol is a competitive non selective beta-adrenergic receptor antagonist used to amend or restore normal heart rhythm in cardiovascular diseases. An in vitro dissolution study was carried out using the United States Pharmacopoeia (USP) paddle method at $75 \mathrm{rpm}$ with $500 \mathrm{~mL}$ of $0.1 \mathrm{~N} \mathrm{HCl}$ dissolution media at $37.0 \pm 0.5{ }^{\circ} \mathrm{C}$. All the tested locally manufactured propranolol products; PRP1, PRP2, PRP3, PRP4 showed compatible dissolution (87\%, 86\%, 87\%, and 80\%, respectively) pattern (dissolution criterion $\mathrm{Q}=80 \%$ in 30 minutes) compared with the reference brand (88\% dissolution in 30 minutes). The dissolution behavior was estimated with the reference brand using a model dependent and model-independent approach $\left(f_{2}>50, f_{1}<15\right)$. A mechanistic mathematical release kinetics was also evaluated. The best-fit kinetic model was Hixon-Crowell release kinetics for reference brand and PRP1; and first order release kinetics was predominant for PRP2, PRP3 and PRP4.
\end{abstract}

Keywords: propranolol, dissolution, similarity factor, difference factor, dissolution kinetics

*Address for Correspondence:

Dr. Shimul Halder, Department of Pharmaceutical Technology, Faculty of Pharmacy, University of Dhaka, Dhaka-1000, Bangladesh.

\section{INTRODUCTION}

Dissolution testing is an empirical in vitro laboratory performance test that characterizes how a drug is released from its dosage form efficiently. It can be used in the calculation of active ingredients and in understanding of potential risks in case of modified release dosage forms, interaction with other medication, food impact on bioavailability, etc. 1-5. Dissolution testing has expanded its contributions in drug product development stage, quality control and approval of regulatory process since its outset in early $1960 \mathrm{~s}^{6}$. In vitro dissolution test is one of the most vital tests to assess release profiles of drugs in pharmaceutical formulations 7-10. It allows the process to be cost-effective and less time-consuming. It has several significant applications as a quality control tool for ensuring batch to batch uniformity, any relationship between in vitro dissolution and in vivo performance (IVIVR), registration and in research and development to examine the performance and stability of new formulations 11-14.

Propranolol is a beta-adrenergic receptor antagonist widely used in numerous conditions such as hypertension, cardiac arrhythmias, myocardial infarction, migraine, portal hypertension, anxiety, essential tremors, hyperthyroidism, and pheochromocytoma 15,16. Its chemical Formula is:
$\mathrm{C}_{16} \mathrm{H}_{22} \mathrm{C}_{1} \mathrm{NO}_{2}$ and Molecular Weight: 295.80 as $\mathrm{HCl}$ form (Fig. 1). In Bangladesh, propranolol is marketed as $10 \mathrm{mg}$ and 40 mg tablet forms. Drug release profiles of different brands may vary due to differences in formulations and other critical manufacturing processes. But the differences must not compromise the bioequivalence as well as quality ${ }^{17}$ Due to availability of different brands in the market, there is a possibility of getting substandard or counterfeit products. Sometimes it becomes difficult for drug regulatory affairs to access the quality of products 18. According to the Biopharmaceutical Classification System (BCS) 19, propranolol is classified as a class I drug and it is soluble in water. These properties can be helpful to assess propranolol by in vitro dissolution for bioequivalence study easily 9 . Pharmaceutical equivalence test can be used to compare the release profiles of generic drugs to that of reference drug.<smiles>CC(C)NCC(O)COc1cccc2ccccc12</smiles>

. $\mathrm{HCl}$

Figure 1: Chemical structure of Propranolol hydrocholoride 
The purpose of this study was to compare the quality of commercially available propranolol tablets to that of a reference brand in terms of in vitro dissolution behavior. To clarify the interchangeability of commercially available propranolol tablets, the dissolution behavior was also statistically treated using both model-dependent and modelindependent approaches.

\section{MATERIALS AND METHODS}

\section{Materials}

Propranolol $\mathrm{HCl}$ reference standard was obtained from ACI Pharmaceuticals Ltd. as a gift. All others commercially available analytical grade chemicals and reagents were used without further purification.

\section{Collection of samples}

Reference brand of Propranolol tablet and locally manufactured four products of Propranolol tablets were purchased commercially from different drug shops of Dhaka city. The samples were properly checked for their Manufacturing license numbers, batch numbers, and production and expiry dates before purchasing. The WHO guidelines were followed during sampling strategies 20,21. They were randomly coded from PRP1 to PRP4 and stored under appropriate condition until further study. The labels of all the products claimed to contain $10 \mathrm{mg}$ of the active ingredient per tablet.

\section{Determination of propranolol}

The amount of propranolol in the commercial products and in reference brand were determined using the UV visible spectrophotometer (DR/ 4000U (HACH, USA)) at an absorbance of $289 \mathrm{~nm}$ according to a previous report 22 . Potency was calculated against the standard solution.

Potency $(\%)=$

$\frac{\text { Absorbance of sample }}{\text { Absorbance of standard }} \times \frac{\text { concentration of standard solution }}{\text { concentration of sample solution }} \times$ potency of standard (\%)

\section{Construction of standard curve}

Propranolol reference standard $20 \mathrm{mg}$ was taken in $20 \mathrm{~mL}$ and made up to the mark with the dissolution media. Concentration was $1 \mathrm{mg} / \mathrm{mL}$. Then $10 \mathrm{~mL}$ of this solution was diluted to $100 \mathrm{~mL}$ with dissolution media. Concentration was $100 \mu \mathrm{g} / \mathrm{mL}$. From this solution further dilution was carried to prepare $(10-24 \mu \mathrm{g} / \mathrm{mL})$ as working solutions for calibration curve. Then absorbance was taken from UV-VIS spectrophotometer according to the method mentioned earlier. The mean regression equation of the curve was $\mathrm{y}=$ $0.0329 \mathrm{x}+0.0129$ (Fig.2). The Linear regression was significant $\left(R^{2}=0.9989 ; p=0.0001\right)$.

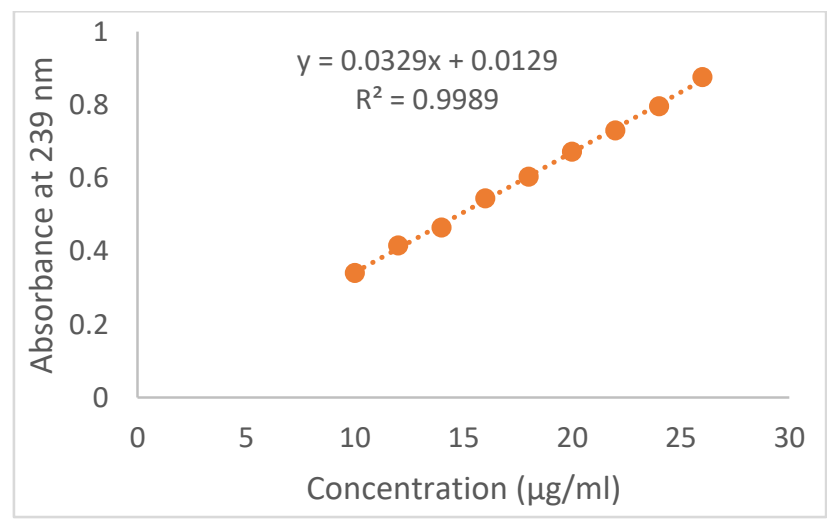

Figure 2: Calibration curve of Propranolol reference standard

\section{Preparation of dissolution media}

The dissolution media containing simulated fasted sate gastric fluid was prepared $(0.1 \mathrm{~N} \mathrm{HCl})$ by adding $9.865 \mathrm{~mL}$ hydrochloric acid (37\% v/v) with sufficient water to produce $1000 \mathrm{~mL}$

\section{Dissolution test of propranolol samples}

Dissolution studies were conducted on an USP standard Dissolution apparatus (Pharmatest, Germany) having six paddle assembly. The dissolution medium was $500 \mathrm{~mL}$ of 0.1 $\mathrm{N} \mathrm{HCl}$ maintained at a temperature of $37 \pm 0.5^{\circ} \mathrm{C}$ and the stirring rate was maintained at $75 \mathrm{rpm}$ as mentioned at USP 23. Six tablets were tested in each case. Samples were withdrawn at $10,20,30$, and 45 minutes time intervals and their absorbance were recorded.

At first, all parts of the dissolution test apparatus were cleaned properly and its tank was filled with tap water up to the specified level. All the six vessels were filled with $500 \mathrm{~mL}$ $0.1 \mathrm{~N} \mathrm{HCl}$ prepared before and the stirrers were set properly with $75 \mathrm{rpm}$ to the machine. Six tablets of each brand were tested in each case. After that, for each brand, four different test tubes were labeled and arranged serially. Then, the machine was started and set for $75 \mathrm{rpm}$ (rotation per minute) for each beaker and the time was set to run for 45 minutes. At 10, 20, 30 and 45 minutes, $5 \mathrm{~mL}$ of the sample from each beaker was taken and filtered into its respective test Tube. At each time point, equal fresh medium was added to maintain the constant total volume in each vessel. After 45 minutes, the machine was stopped and cleaned properly and the sample solutions were arranged accordingly for spectrometric analysis.

\section{Model independent fit factors}

Fit factors compare a test's percent of drug dissolve per unit time to a reference's percent of drug dissolve per unit time. The difference factor $\left(f_{1}\right)$ calculates the percentage difference between the two curves (reference and test drug) at each time point; whereas, the similarity factor $\left(f_{2}\right)$ is a logarithmic reciprocal square root transformation of the sum of squared error and is a measurement of the similarity in the percent (\%) dissolution from the following equations.

$$
\begin{aligned}
f_{1} & =\left\{\frac{\sum\left(R_{t}-T_{t}\right)}{\sum R_{t}}\right\} \times 100 \text { Where, } t=1 \text { to } n \\
f_{2} & =50 \log \left\{\left[1+\frac{1}{n} \sum_{t=1}^{n}\left(R_{t}-t_{t}\right)^{2}\right]^{-0.5} \times 100\right\}
\end{aligned}
$$

Where $\mathrm{n}$ is the number of time points, $R_{t}$ is the dissolution value of the reference product at time $\mathrm{t}$, and $T_{t}$ is the dissolution value of the test product at time $t$.

The parameter $f_{1}$, whose values range from 0 to 15 , and for $f_{2}$, whose values range from 50 to 100 , are used to define in vitro equivalence between test and reference samples 24,25.

Another model independent factor, mean dissolution time (MDT) is determined from the accumulative curves of dissolved DES as function of time ${ }^{26}$.

$$
M D T=\frac{\sum\left[t_{i} \cdot \Delta Q_{i}\right]}{Q_{\infty}}
$$

Where $t_{i}$ is an intermediate time of the intervals of sampling time, $\Delta \mathrm{Q}_{\mathrm{i}}$ is the amount of PRP dissolved in every interval of $\mathrm{t}$ and $Q_{\infty}$ is the maximum of PRP dissolved.

In addition, Dissolution efficiency (DE) is the area under the dissolution curve within a time range, and it was calculated by using the following equation:

$$
D E(\%)=\frac{\int_{0}^{t} y \times d t}{y_{100} \times t} \times 100 \%
$$


Where, $\mathrm{y}$ is the drug percent dissolved at time $\mathrm{t}$.

\section{Model dependent dissolution kinetics}

To investigate the in vitro release kinetics, various modeldependent mathematical models $\mathbf{2 7 , 2 8}$ such as zero-order, first-order, Higuchi, Hixson-Crowell, Korsmeyer-Peppas, and Weibull were used. Following are the equations to describe the model dependent mathematical kinetics:

Zero Order kinetics:

$Q_{t}=Q_{0}+K_{0} t$

First Order kinetics:

$\ln Q_{t}=\ln Q_{0}+K_{1} t$

Higuchi kinetics:

$Q_{t}=K_{h} t^{1 / 2}$

Hixson-Crowell kinetics:

$Q_{0}^{1 / 3}+Q_{t}^{1 / 3}=K_{d}$

Korsmeyer Peppas kinetics:

$\frac{Q_{t}}{Q_{\infty}}=K_{k p} t^{n}$

Weibull kinetics:

$\log [-\ln (1-m)]=\beta \log \left(t-T_{i}\right)-\log \alpha$

Where, $Q_{t}$ is the amount of drug dissolved in time t, $Q_{0}$ is the initial amount of drug in the solution, $k_{0}$ is the zero-order release constant, $k_{1}$ is the first-order release constant, $K_{h}$ is the Higuchi rate constant, $K_{d}$ is the dissolution constant of Hixson-Crowell kinetics, $Q_{t} / Q_{\infty}$ is a fraction of drug released at time t, $K_{k p}$ is the Korsmeyer release rate constant, $m$ is accumulated fraction of the drug, $\beta$ is shape parameter, $T_{i}$ is the location parameter, $\alpha$ is the scale parameter.

\section{Statistical analysis}

All data are represented as mean \pm standard deviation (SD). The mathematical parameters were calculated using DDSolver program 29. Graphs were charted using Graphpad, Prism 6.0, (GraphPad Software, LaJolla, CA).

\section{RESULTS AND DISCUSSION}

\section{In vitro dissolution studies}

From the Fig. 3 of the release profile graph, we observed that the reference brand REF and the marketed product PRP1 gave the best response in the shortest possible time. After 10 minutes, more than $50 \%$ propranolol was dissolved from REF and PRP1 (53.35\% and 50.01\%, respectively). However, the remaining brands showed moderate dissolution pattern by this first 10 minutes. After 20 minutes, REF and PRP3 crossed the level of $65 \%$ i.e. more than $65 \%$ propranolol was dissolved. But, PRP4 showed a little slow dissolution (58.32\%) compared with REF, PRP1, PRP2, and PRP3 (68.62\%, 64.16\%, 64.18\%, 67.32\%, respectively). After 30 minutes, REF and PRP1, PRP2 and PRP3 crossed the level of $85 \%$ i.e. more than $85 \%$ of propranolol was dissolved after 30 minutes. On the other hand, PRP4 showed $79.95 \%$ dissolution that might be a poor dissolution pattern compared to other brands. After 45 minutes of dissolution studies, three local products PRP1, PRP2, PRP3 crossed the level of $90 \%$ which indicates the desired dissolution pattern attained by these three local brands with the reference brand REF that is of $98.18 \%$. Here PRP4 showed a little poor dissolution pattern $88.70 \%$ compared to other products however PRP4 also met the official requirement 23

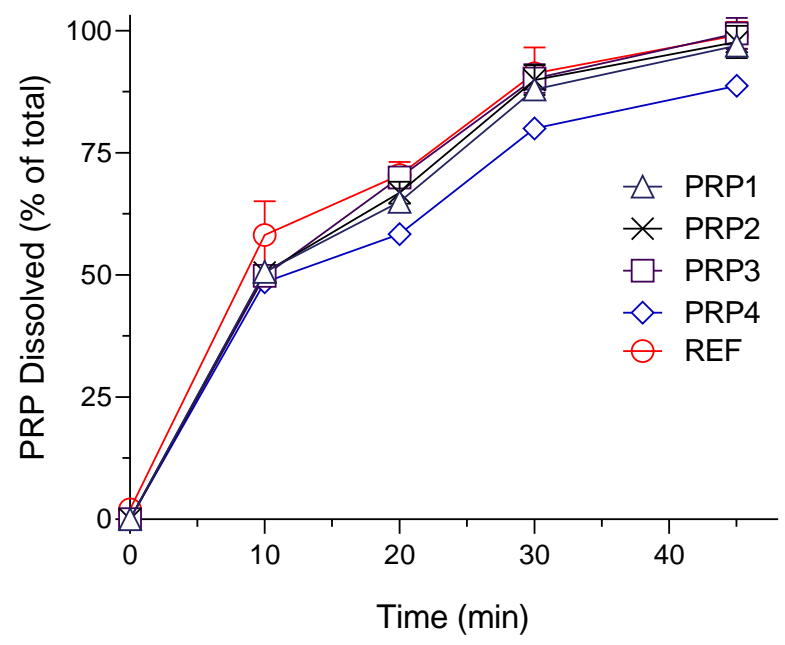

Figure 3: Comparative in vitro dissolution profiles of different PRP samples at simulated gastric fluid (0.01N HCl). Each bar represents mean \pm S.D. of 3 experiments.

\section{Dissolution profile comparison}

Non-linear one-way ANOVA was used to analyze the dissolution profiles of the propranolol samples, including the reference brand, by fitting both model dependent and modelindependent fit factors. Fit factors are key quantitative metrics explaining and comparing dissolution profiles among different samples with reference brand, according to the United States Food and Drug Administration (USFDA). The similarity factor, $f_{2}$, is more accurate in determining dissimilarities among samples, according to USFDA recommendations, and an $f_{2}$ value greater than 50 suggests same dissolution behavior. The difference factor, $f_{1}$, on the other hand, clarifies the difference in dissolution profile based on sample times. The value of $f_{1}$ must be in the range of 0 to 15 . From the result at $95 \%$ confidence interval (CI) for the model independent fit factors as per USP specified time, it found that there were no significant differences in the release pattern of various PRP samples (Table 1$)(P<0.05)$. This implies all the available PRP products in market might statistically comparable with respect to their in vitro release profile paralleled to reference brand. 
Table 1: Various dissolution related model independent fit factors of different of PRP samples

\begin{tabular}{cccccc}
\hline Sample & $\begin{array}{c}\text { Similarity factor } \\
\left(f_{2}\right)\end{array}$ & $\begin{array}{c}\text { Difference factor } \\
\left(f_{1}\right)\end{array}$ & $\begin{array}{c}\text { MDT } \\
(\mathrm{min})\end{array}$ & $\begin{array}{c}\text { T75 } \\
(\mathrm{min})\end{array}$ & \multicolumn{2}{c}{ Dissolution efficiency } \\
$(\%)$
\end{tabular}

$f_{2}$, Similarity factor; $f_{1}$, difference factor $\left(f_{1}\right)$; MDT, mean dissolution time; $\mathrm{T}_{50}$, time to dissolve $50 \%$ of PRP; $\mathrm{T}_{75}$, time to dissolve $75 \%$ of PRP; and DE, dissolution efficiency

DE and MDT values, on the other hand, are model independent characteristics that can determine interchangeability between different formulations. The results (Table 1) show that all test samples are equivalent to the reference brand, with a DE difference of less than $10 \% 30$. From the results of model independent fit factors, all PRP samples can be considered as interchangeable with reference brand.

Furthermore, multiple model dependent kinetic models such as zero order, first order, Higuchi, Hixon-Crowell, Korsmeyer-
Peppas, and Weibull models were examined by fitting experimental data in this study. The model with the highest correlation coefficient $\left(\mathrm{R}^{2}\right)$ value is regarded the best fitted model of the release data after fitting models to the individual kinetic model of the dissolution data 31. In Table 2, correlation coefficient, adjusted correlation coefficient, and dissolution constant values are presented to identify and clarify the best fitted model. From table 2, the Hixon-Crowell model provides the highest correlation coefficient both actual and adjusted for reference brand and PRP1 and first order release kinetics provides for PRP2, PRP3, and PRP4.

Table 2: Determination of dissolution kinetics of different model dependent release kinetic models

\begin{tabular}{|c|c|c|c|c|c|c|}
\hline \multirow{2}{*}{ Model } & \multirow{2}{*}{ Parameters } & \multicolumn{5}{|c|}{ Samples } \\
\hline & & $\mathrm{REF}$ & PRP1 & PRP2 & PRP3 & PRP4 \\
\hline \multirow{3}{*}{ Zero Order } & $R^{2}$ & 0.9518 & 0.9392 & 0.9261 & 0.9320 & 0.9421 \\
\hline & Adjusted $R^{2}$ & 0.9277 & 0.9088 & 0.8892 & 0.8980 & 0.9132 \\
\hline & $K_{0}$ & 2.620 & 2.539 & 2.506 & 2.551 & 2.348 \\
\hline \multirow{3}{*}{ First-order } & $R^{2}$ & 0.9607 & 0.9764 & 0.9772 & 0.9893 & 0.9686 \\
\hline & Adjusted $R^{2}$ & 0.9410 & 0.9646 & 0.9658 & 0.9840 & 0.9529 \\
\hline & $K_{1}$ & 0.00027 & 0.00032 & 0.00035 & 0.00032 & 0.00040 \\
\hline \multirow{3}{*}{ Higuchi } & $R^{2}$ & 0.9772 & 0.9631 & 0.9589 & 0.9715 & 0.9536 \\
\hline & Adjusted $R^{2}$ & 0.9658 & 0.9447 & 0.9383 & 0.9572 & 0.9303 \\
\hline & $K_{h}$ & 35.368 & 34.096 & 33.659 & 34.247 & 31.611 \\
\hline \multirow{3}{*}{ Hixon-Crowell } & $R^{2}$ & 0.9893 & 0.9782 & 0.9688 & 0.9891 & 0.9640 \\
\hline & Adjusted $R^{2}$ & 0.9839 & 0.9673 & 0.9532 & 0.9836 & 0.9460 \\
\hline & $K_{d}$ & 0.00026 & 0.00024 & 0.00023 & 0.00024 & 0.00019 \\
\hline \multirow{4}{*}{ Korsmeyer-Peppas } & $R^{2}$ & 0.9831 & 0.9705 & 0.9718 & 0.9826 & 0.9516 \\
\hline & Adjusted $R^{2}$ & 0.9747 & 0.9558 & 0.9578 & 0.9739 & 0.9275 \\
\hline & $K_{k p}$ & 1.720 & 1.689 & 1.680 & 1.681 & 1.670 \\
\hline & $n$ & 0.294 & 0.320 & 0.327 & 0.338 & 0.303 \\
\hline \multirow{3}{*}{ Weibull } & $R^{2}$ & 0.8622 & 0.8190 & 0.8216 & 0.8660 & 0.8041 \\
\hline & Adjusted $R^{2}$ & 0.7932 & 0.7285 & 0.7325 & 0.7990 & 0.7061 \\
\hline & $\beta$ & 1.018 & 9.201 & 5.061 & 0.748 & 0.686 \\
\hline
\end{tabular}

$R^{2}$, correlation coefficient; adjusted $R^{2}$, adjusted correlation coefficient using nonlinear regression; $k_{0}$, zero-order release constant; $k_{1}$, first-order release constant; $K_{h}$, Higuchi rate constant; $K_{d}$, Hixson-Crowell kinetics constant; $K_{k p}$, Korsmeyer release rate constant; $n$, diffusion coeeficent; $\beta$, shape parameter. 


\section{CONCLUSION}

The goal of the in vitro dissolution study was to look at the release profiles of four local products and compare them to a reference brand. For the reference brand and PRP1, the Hixon-Crowell model was dominating, while first order release kinetics was prevalent for PRP2, PRP3, and PRP4. According to the USP criteria, all four local products had a suitable dissolution pattern with the reference brand (at least $80 \%$ of the propranolol was dissolved in the medium after 30 minutes). The dissolution efficiency (DE) difference was less than $10 \%$. The four products of propranolol $10 \mathrm{mg}$ generic tablets available in Bangladesh are found to be equivalent to the reference brand. They may have similar biopharmaceutical equivalence and can be used to treat hypertension interchangeably.

\section{Acknowledgement}

The authors wish to thank ACI Pharmaceuticals Ltd., Dhaka, Bangladesh for their generous help in providing the propranolol reference drug.

\section{Conflict of interest}

The authors declare no conflict of interest related to this article.

\section{REFERENCES}

1. Zaborenko N, Shi Z, Corredor CC, Smith-Goettler BM, Zhang L, Hermans A, et al. First-Principles and Empirical Approaches to Predicting In Vitro Dissolution for Pharmaceutical Formulation and Process Development and for Product Release Testing. AAPS J. 2019; 21(3):21-32. https://doi.org/10.1208/s12248-0190297-y

2. Eedara BB, Tucker IG, Das SC. In vitro dissolution testing of respirable size anti-tubercular drug particles using a small volume dissolution apparatus. Int J Pharm. 2019; 559:235-44. https://doi.org/10.1016/j.ijpharm.2019.01.035

3. Walsh EG, Adamczyk BE, Chalasani KB, Maher S, O'Toole EB, Fox JS, et al. Oral delivery of macromolecules: Rationale underpinning Gastrointestinal Permeation Enhancement Technology (GIPET®). Ther Deliv. 2011; 2(12):1595-610. https://doi.org/10.4155/tde.11.132

4. Smith AP, Moore TW, Westenberger BJ, Doub WH. In vitro dissolution of oral modified-release tablets and capsules in ethanolic media. Int J Pharm. 2010; 398(1-2): 93-6. https://doi.org/10.1016/j.ijpharm.2010.07.031

5. Ilyés K, Balogh A, Casian T, Igricz T, Borbás E, Démuth B, et al. 3D floating tablets: Appropriate 3D design from the perspective of different in vitro dissolution testing methodologies. Int J Pharm. 2019; 567:118433. https://doi.org/10.1016/j.ijpharm.2019.06.024

6. Mehtani D, Seth A, Sharma P, Maheshwari R, Abed SN, Deb PK, et al. Dissolution Profile Consideration in Pharmaceutical Product Development. Dosage Form Design Considerations: Volume I. Elsevier Inc.; 2018; 287-336 p. https://doi.org/10.1016/B978$0-12-814423-7.00009-5$

7. Molavi F, Hamishehkar H, Nokhodchi A. Impact of tablet shape on drug dissolution rate through immediate released tablets. Adv Pharm Bull. 2020; 10(4):656-61. https://doi.org/10.34172/apb.2020.079

8. Dey B, Katakam P, Assaleh FH, Chandu BR, Adiki SK, Mitra A. In vitro-in vivo studies of the quantitative effect of calcium, multivitamins and milk on single dose ciprofloxacin bioavailability. J Pharm Anal. 2015; 5(6):389-95. https://doi.org/10.1016/j.jpha.2015.02.003

9. Amidon GL, Lennernäs H, Shah VP, Crison JR. A Theoretical Basis for a Biopharmaceutic Drug Classification: The Correlation of in Vitro Drug Product Dissolution and in Vivo Bioavailability. Vol.
12, Pharmaceutical Research: An Official Journal of the American Association of Pharmaceutical Scientists. 1995. p. 413-20.

10. Lin Z, Zhou D, Hoag S, Qiu Y. Influence of Drug Properties and Formulation on In Vitro Drug Release and Biowaiver Regulation of Oral Extended Release Dosage Forms. AAPS J. 2016; 18(2):333-45. https://doi.org/10.1208/s12248-015-9861-2

11. Uppoor VRS. Regulatory perspectives on in vitro (dissolution)/in vivo (bioavailability) correlations. J Control Release. 2001; 72(13):127-32. https://doi.org/10.1016/S0168-3659(01)00268-1

12. De Spiegeleer B, Van Vooren L, Voorspoels J, Thoné D, Rosier J. Dissolution stability and IVIVC investigation of a buccal tablet. Anal Chim Acta. 2001; 446(1-2):343-9. https://doi.org/10.1016/S0003-2670(01)01074-1

13. Nguyen MA, Flanagan T, Brewster M, Kesisoglou F, Beato S, Biewenga J, et al. A survey on IVIVC/IVIVR development in the pharmaceutical industry - Past experience and current perspectives. Eur J Pharm Sci. 2017; 102:1-13. https://doi.org/10.1016/j.ejps.2017.02.029

14. Goodhart FW, McCoy RH, Ninger FC. New In Vitro Disintegration and Dissolution Test Method for Tablets and Capsules. J Pharm Sci. 1973 Feb 1; 62(2):304-10. https://doi.org/10.1002/jps.2600620227

15. Srinivasan A V. Propranolol: A 50-year historical perspective. Ann Indian Acad Neurol. 2019; 22(1):21-6. https://doi.org/10.4103/aian.AIAN_201_18

16. Liu X, Qu X, Zheng J, Zhang L. Effectiveness and safety of oral propranolol versus other treatments for infantile hemangiomas: A meta-analysis. PLoS One. 2015; 10(9):1-16. https://doi.org/10.1371/journal.pone.0138100

17. Menegola J, Steppe M, Schapoval EES. Dissolution test for citalopram in tablets and comparison of in vitro dissolution profiles. Eur J Pharm Biopharm. 2007; 67(2):524-30. https://doi.org/10.1016/j.ejpb.2007.02.009

18. Glass B. Counterfeit drugs and medical devices in developing countries. Res Rep Trop Med. 2014; 11. https://doi.org/10.2147/RRTM.S39354

19. Cook J, Addicks W, Wu YH. Application of the Biopharmaceutical Classification System in Clinical Drug Development-An Industrial View. AAPS J. 2008; 10(2):306-10. https://doi.org/10.1208/s12248-008-9036-5

20. Palinkas LA, Horwitz SM, Green CA, Wisdom JP, Duan N, Hoagwood K. Purposeful Sampling for Qualitative Data Collection and Analysis in Mixed Method Implementation Research. Adm Policy Ment Heal Ment Heal Serv Res. 2015. 42(5):533-44. https://doi.org/10.1007/s10488-013-0528-y

21. Pheatt CB. Evaluation of U. S. Pharmacopeia Sampling Plans for Dissolution. J Qual Technol. 1980;12(3):158-64 https://doi.org/10.1080/00224065.1980.11980955

22. Conceição AP, Sá RR, da Silva VC, Ferreira M da S, Cazedey ECL Magalhães HIF, et al. A comparative study of propranolol release by in vitro dissolution profiles in pharmaceutical formulations. Dissolution Technol. 2018; 25(4):54-61. https://doi.org/10.14227/DT250418P54

23. Hydrochloride P. Propranolol Hydrochloride Tablets » Propranolol Hydrochloride Tablets contain not less than 90 . 0 percent and not more than 110 . 0 Propranolol Hydrochloride and Hydrochlorothiazide Extended-Release Capsules » Propranolol Hydrochloride and Hydrochlorothi. 2012; (c):20113.

24. Polli JE, Rekhi GS, Augsburger LL, Shah VP. Methods to Compare Dissolution Profiles and a Rationale for Wide Dissolution Specifications for Metoprolol Tartrate tablets†. J Pharm Sci. 1997 Jun 1; 86(6):690-700. https://doi.org/10.1021/js960473x

25. Anderson NH, Bauer M, Boussac N, Khan-Malek R, Munden P, Sardaro M. An evaluation of fit factors and dissolution efficiency for the comparison of in vitro dissolution profiles. J Pharm Biomed Anal. 1998; 17(4-5):811-22. https://doi.org/10.1016/S0731-7085(98)00011-9 
26. Mircioiu C, Voicu V, Anuta V, Tudose A, Celia C, Paolino D, et al. Mathematical modeling of release kinetics from supramolecular drug delivery systems. Pharmaceutics. 2019; 11(3):1-45. https://doi.org/10.3390/pharmaceutics11030140

27. Mohapatra S, Kar RK, Sahoo SK. Goodness of fit model dependent approaches of controlled release matrix tablets of zidovudine. Indian J Pharm Educ Res. 2016; 50(1):138-45. https://doi.org/10.5530/ijper.50.1.18

28. Simionato LD, Petrone L, Baldut M, Bonafede SL, Segall AI. Comparison between the dissolution profiles of nine meloxicam tablet brands commercially available in Buenos Aires, Argentina. Saudi Pharm J [Internet]. 2018; 26(4):578-84. https://doi.org/10.1016/j.jsps.2018.01.015

29. Zhang Y, Huo M, Zhou J, Zou A, Li W, Yao C, et al. DDSolver: An add-in program for modeling and comparison of drug dissolution profiles. AAPS J. 2010; 12(3):263-71. https://doi.org/10.1208/s12248-010-9185-1

30. Umeta B, Bekele A, Mohammed T, Duguma M, Teshome H, Mekonnen Y. Dissolution profile evaluation of eight brands of metformin hydrochloride tablets available in Jimma, Southwest Ethiopia. Diabetes, Metab Syndr Obes Targets Ther. 2021; 14:3499-506. https://doi.org/10.2147/DMSO.S316187

31. Abraham W, Abuye H, Kebede S, Suleman S. In Vitro Comparative Quality Assessment of Different Brands of Doxycycline Hyclate Finished Dosage Forms: Capsule and Tablet in Jimma Town, South-West Ethiopia. Youssef TE, editor. Adv Pharmacol Pharm Sci. 2021; 2021:6645876. https://doi.org/10.1155/2021/6645876 